\title{
Spatial Variability of Water Optical Characteristics in the Southern Mediterranean Sea in Spring (May, 1998)
}

\author{
V. I. Mankovsky*, E. V. Mankovskaya \\ Marine Hydrophysical Institute of RAS, Sevastopol, Russian Federation \\ *mankovskiy@mhi-ras.ru
}

Purpose. The aim of the paper is to study spatial variability of the Mediterranean Sea water optical features as well as to supply the database with additional information on the water optical characteristics required for constructing the regional hydrooptical models.

Methods and Results. The data on optical characteristics of the southern Mediterranean Sea waters resulted from the passing measurements in the $2^{\text {nd }}$ cruise of R/V Gorizont in May, 1998 are used in the study. In the water samples from the sea surface layers, the spectral coefficients of beam attenuation and light scattering phase function were measured. Spatial variability of the seawater hydrooptical characteristics from the Strait of Gibraltar to the Dardanelles is considered and analyzed. The equation for the relationship between the asymmetry coefficient of the scattering phase function and the scattering coefficient in the Mediterranean Sea waters is obtained.

Conclusions. The data characterizing spatial variability of the southern Mediterranean Sea water optical features in spring are obtained. The coefficients of beam attenuation and scattering in the surface waters decrease gradually from the western Mediterranean Sea to its eastern part. In the Aegean Sea near the Dardanelles, the Marmara Sea waters differing by their high coefficients of beam attenuation and scattering were observed. As for the basic parameters, the scattering phase functions in the Mediterranean Sea waters are similar to those in the Atlantic tropical waters. In the Mediterranean Sea waters as well as in the other water basins, the relationship between the asymmetry coefficient of the light scattering phase function and the scattering coefficient is observed; it is manifested in increase of the phase function asymmetry coefficient with the scattering coefficient.

Keywords: optical characteristics, beam attenuation coefficient, light scattering phase function, phytoplankton, yellow matter.

Acknowledgments: the study was carried out within the framework of the state task on themes No. 0827-2019-0002 and No. 0827-2019-0004.

For citation: Mankovsky, V.I. and Mankovskaya, E.V., 2020. Spatial Variability of Water Optical Characteristics in the Southern Mediterranean Sea in Spring (May, 1998). Physical Oceanography, [e-journal] 27(1), pp. 48-59. doi:10.22449/1573-160X-2020-1-48-59

DOI: $10.22449 / 1573-160 X-2020-1-48-59$

(C) V.I. Mankovsky, E.V. Mankovskaya, 2020

(C) Physical Oceanography, 2020

\section{Introduction}

Study of the hydrooptical characteristics of the Mediterranean Sea is an actual task in oceanology. This research has been carried out for many years as part of the international programs: POEM (Physical Oceanography of the Eastern Mediterranean), CIESM (The Mediterranean Science Commission, or Commission 
Internationale pour l'Exploration Scientifique de la Méditerranée) and MEDCOAST (Mediterranean Coastal Foundation) [1-4].

Since 1972, Marine Hydrophysical Institute (MHI) has been included in the study of the optical properties of Mediterranean waters under the national programs "The World Ocean" and "Satellite Oceanology". From 1972 to 1992 MHI carried out optical studies in thirteen expeditions in the Mediterranean Sea. A summary of these expeditions is given in [5].

These studies resulted in obtaining extensive data on the optical properties of the Mediterranean Sea waters: spectral beam attenuation coefficient, light scattering phase functions, reflectance band ratio, water column reflectance, Secchi disk depth [5-11]. Most of this data relates to the eastern part of the sea.

In May 1998, on the second cruise of R/V Gorizont from Sevastopol to Lisbon to the international oceanographic exhibition EXPO-98 passing measurements of the optical characteristics of waters in the southern Mediterranean Sea were carried out by Marine Hydrophysical Institute as a part of the Satellite Oceanology program. The research was aimed to study the spatial variability of the optical properties of Mediterranean Sea waters, as well as to supply the database with information on the optical characteristics of water necessary for constructing regional hydro-optical models.

The spectral beam attenuation coefficient and the light scattering phase functions were measurements in water samples taken from the sea surface layers. As a result, data on the optical characteristics of surface waters from the Strait of Gibraltar to the Dardanelles was obtained. The data peculiarity is that it was obtained in a short time and characterize the spatial variability of the optical properties of water in the southern Mediterranean in spring season.

Currently, the relevance of information obtained is determined by the development of regional hydrophysical models, the verification of which is carried out according to field data, including the archival one. This data is also used for reanalysis of hydrophysical fields in assimilation models; it can be used to compare with modern data from optical scanners used for remote sensing of the Mediterranean Sea.

\section{Instrumentation and Measurement Methodology}

The beam attenuation coefficient (BAC) was measured by a transparency meter [12] in seven spectral regions: 416, 468, 506, 567, 610, 625 and $677 \mathrm{~nm}$ (Tab.1). The light scattering phase function was measured with a nephelometer ${ }^{1}$ at a wavelength of $520 \mathrm{~nm}$ (Tab. 1). Water samples were taken from the sea surface.

1 Mankovsky, V.I., 1981. [Marine Pulse Nephelometer. Devices for Scientific Research and Automation Systems in the Academy of Sciences of the Ukrainian SSR]. Kiev: Naukova Dumka]. pp. 87-89.

PHYSICAL OCEANOGRAPHY VOL. 27 ISS. 1 (2020) 
Technical characteristics of the devices

\begin{tabular}{lc}
\hline \multicolumn{1}{c}{ Parameter name } & Value \\
\hline \multicolumn{1}{c}{ Transparency meter } \\
\hline Spectral range of BAC measurement, nm & $416-677$ \\
Number of spectral channels, pcs. & 13 \\
BAC measurement range of, $\mathrm{m}^{-1}(\mathrm{ln})$ & $0.05-2.0$ \\
BAC measurement Error, $\%$ & 5 \\
\hline \multicolumn{2}{c}{ Nephelometer } \\
\hline Measurement angles of the scattering coefficient $\sigma(\theta), \theta,^{\circ}$ & $2 ; 7.5$ further every 5 up to 162.5 \\
Spectral area of measurements, nm & 520 \\
Error of measurements $\sigma(\theta), \%$ & 10 \\
\hline
\end{tabular}

\section{Measurement Results and their Discussion}

Fig. 1 shows the areas of measurement of optical characteristics along the vessel route. Tab. 2 gives the description of the regions.

Beam attenuation coefficient. Fig. 2 shows the BAC value at a wavelength of $416 \mathrm{~nm}$ in the measurement regions. A specific feature of spatial variability in the basin from the Alboran Sea to the Levantean Sea is a gradual decrease in the beam attenuation coefficient $\varepsilon(416)$ from 0.368 to $0.159 \mathrm{~m}^{-1}$. A decrease in $\varepsilon$ in this part of the basin was also observed at other wavelengths (Tab. 3).

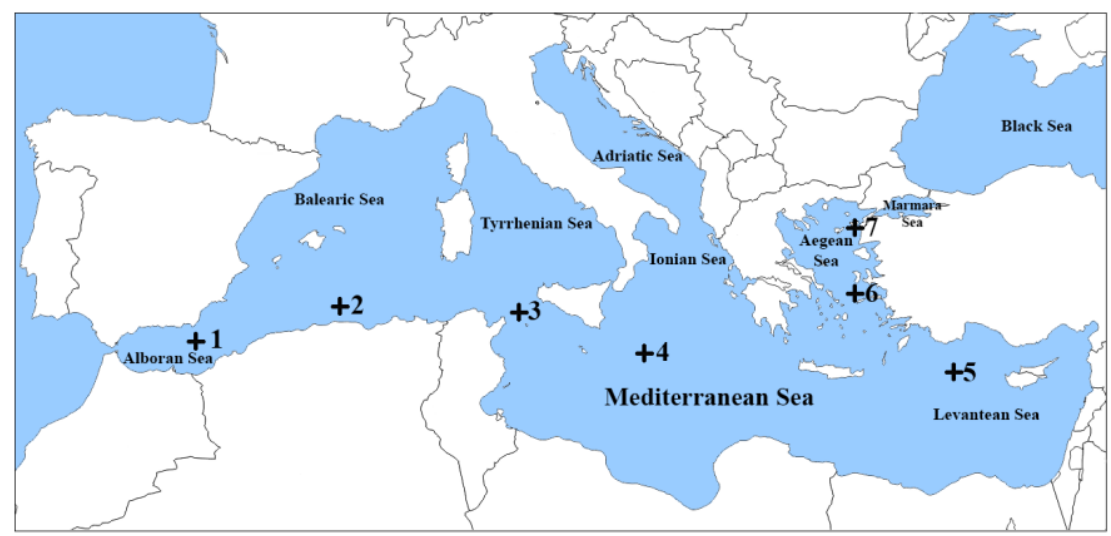

F i g. 1. Route of the $2^{\text {nd }}$ cruise of R/V Gorizont (crosses with numbers 1-7 denote the regions where hydrooptical characteristics were measured (Table 2))

High values of the beam attenuation coefficient $\varepsilon(416)\left(1.242 \mathrm{~m}^{-1}\right)$ observed in the northern Aegean Sea near the Dardanelles refers to the waters of the Marmara Sea entering the Aegean through the strait. The waters of the Marmara Sea that emerged from the strait, having lower salinity and, accordingly, lower density, than the waters of the Aegean Sea, spread in its surface layers. 
The regions where optical characteristics were measured

\begin{tabular}{cll}
\hline Number & \\
\hline 1 & The Alboran Sea, the central part \\
2 & The Balearic Sea, the southern part \\
3 & The Sicily Strait \\
4 & The Ionian Sea, the southern part \\
5 & The Levanteane Sea. Rhodes anticyclone \\
6 & The Aegean Sea, the middle part \\
7 & The Aegean Sea near the Dardanelles \\
\hline
\end{tabular}

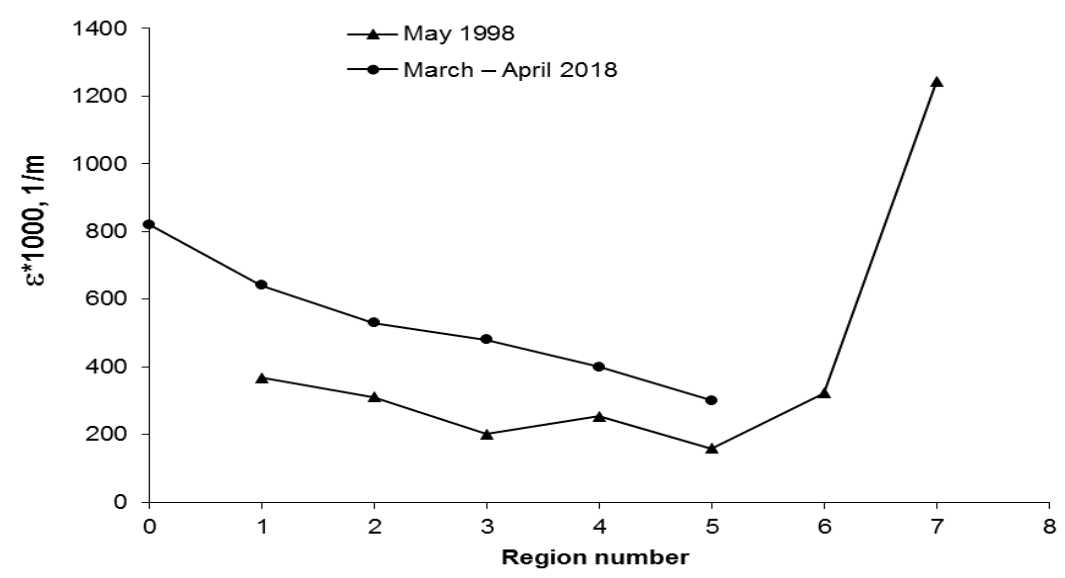

F i g. 2. The beam attenuation coefficient in different regions of the Mideterranean Sea, $\varepsilon(416)$, May, 1998 (४); $\varepsilon$ (the average value in the 0-200 m layer), March - April, 2018 (•)

T a b l e 3

The beam attenuation coefficient $\left(\varepsilon(\lambda) \cdot 10^{3}\right)$ in the regions of measurements

\begin{tabular}{c|c|c|c|c|c|c|c}
\hline \multirow{2}{*}{$\begin{array}{c}\text { Wavelength } \\
\lambda, \mathrm{nm}\end{array}$} & \multicolumn{7}{|c}{$\varepsilon(\lambda) \cdot 10^{3}, \mathrm{~m}^{-1}$} \\
\cline { 2 - 8 } & 1 & 2 & 3 & 4 & 5 & 6 & 7 \\
\hline 416 & 368 & 311 & 201 & 253 & 159 & 322 & 1242 \\
\hline 468 & 299 & 219 & 133 & 196 & 101 & 246 & 1047 \\
\hline 506 & 276 & 190 & 120 & 179 & 104 & 230 & 1009 \\
\hline 567 & 311 & 245 & 177 & 223 & 152 & 253 & 1000 \\
\hline 610 & 478 & 404 & 361 & 391 & 322 & 414 & 1150 \\
\hline 625 & 529 & 472 & 437 & 467 & 373 & 483 & 1200 \\
\hline 677 & 644 & 610 & 566 & 598 & 512 & 633 & 1840 \\
\hline
\end{tabular}

PHYSICAL OCEANOGRAPHY VOL. 27 ISS. 1 (2020) 
In the Mediterranean Sea, a similar spatial variability of the beam attenuation coefficient in the spring period was observed in March - April 2018 according to the data of [3].

The vessel's route [3] passed from the Strait of Gibraltar to the Levant Sea (Fig. 3). Stations with $3000 \mathrm{~m}$ depth sounding were carried out along the route. According to averaged data [3, Fig. 2], the vertical distribution of the beam attenuation coefficient in the western and eastern parts of the sea was the same and was characterized by a slight change with depth.

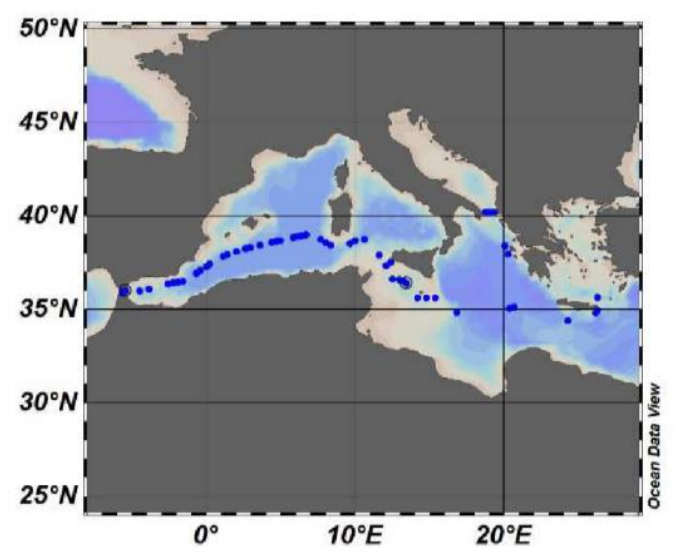

F i g. 3. The route of the vessel in the Mediterranean Sea in [3] in March - April, 2018 (the dots show location of the stations where the attenuation coefficient was measured)

Tab. 4 shows the mean values of the attenuation coefficient in the $0-200 \mathrm{~m}$ layer in some areas according to [3, Tab. 1]. Unfortunately, in the aforementioned work, the wavelength for attenuation coefficient is not indicated. According to the attenuation coefficient values, the measurements were carried out in the red spectrum range, since according to our data the attenuation coefficients at a wavelength of $625 \mathrm{~nm}$ (Tab. 3) have similar values. Nevertheless, the spatial variability of the attenuation coefficient given in [3] is of primary importance.

The Tab. 4 data shows a decrease in attenuation in all areas from the Strait of Gibraltar to the eastern Mediterranean (the Ionian Sea and Levantean Sea). As a result, the value of the attenuation coefficient $\varepsilon$ decreased from 0.82 to $0.30 \mathrm{~m}^{-1}$.

T a bl e 4

Average value of the attenuation coefficient $(\varepsilon)$ in the $0-200 \mathrm{~m}$ layer in different regions of the Mediterranean Sea based on [3, Table 1]

\begin{tabular}{c|c|c|c|c}
\hline \multicolumn{6}{|c}{ Average value of the attenuation coefficient, $\varepsilon, \mathrm{M}^{-1}$} \\
\hline $\begin{array}{c}\text { The Strait of } \\
\text { Gibraltar }\end{array}$ & $\begin{array}{c}\text { The Algerian } \\
\text { basin }\end{array}$ & Corsica & the Sicily & $\begin{array}{c}\text { The eastern } \\
\text { Mediterranean } \\
\text { Sea }\end{array}$ \\
\hline $0.82 \pm 0.10$ & $0.64 \pm 0.12$ & $0.53 \pm 0.07$ & $0.48 \pm 0.10$ & $0.30 \pm 0.09$ \\
\hline
\end{tabular}


The Mediterranean Sea is generally characterized by a low content of nutrients and a low level of chlorophyll [13, 14]. The spatial variability of the beam attenuation coefficient in the Mediterranean Sea is explained by the spatial variability of the productivity of surface North Atlantic waters entering it through the Strait of Gibraltar. The content of nutrients in these waters is small $[15,16]$, and it decreases as the waters move along the southern part of the sea from the Gibraltar Strait to the east due to the consumption of nutrients by phytoplankton. The surface waters are slightly replenished by biogenic matters from deep waters, since the accumulation of nutrients in the deep waters of the sea is hindered by the continuous outflow of these waters back to the Atlantic Ocean through the Strait of Gibraltar [15]. Vertical transport exists in limited frontal and few upwelling areas [14]. Due to these factors, the biological productivity of surface sea water and, accordingly, the concentration of phytoplankton in them decrease, which leads to an increase of the water transparency [17, p. 229-234].

The above facts does not apply to the Aegean Sea waters, since the North Atlantic waters do not enter this sea.

Tab. 3 and Fig. 4 show the attenuation coefficient spectra $\varepsilon(\lambda)$ in different regions of the Mediterranean Sea. The spectrum shape in the Aegean Sea waters near the Dardanelles, where the waters of the Marmara Sea were registered, differs by the position of the minimum $\varepsilon(\lambda)_{\min }$ - in the Mediterranean Sea it is at wavelengths of 468-506 nm, in the waters of the Marmara Sea - at $567 \mathrm{~nm}$. Such a shift in the minimum in the attenuation coefficient spectrum occurs at high concentrations of dissolved organic matter (yellow matter) in water. The absorption coefficient of yellow matter is maximal in the short-wave spectrum region and decreases with the law as $\kappa(\lambda)_{y m} \sim \mathrm{e}^{-\mu \lambda}$ with increasing wavelength. With an increase in the yellow matter concentration, the effect of $\kappa(\lambda)_{y m}$ on the increase of attenuation coefficient reaches longer wavelengths, which leads to a shift of the minimum $\varepsilon(\lambda)$ to the long wavelength region.

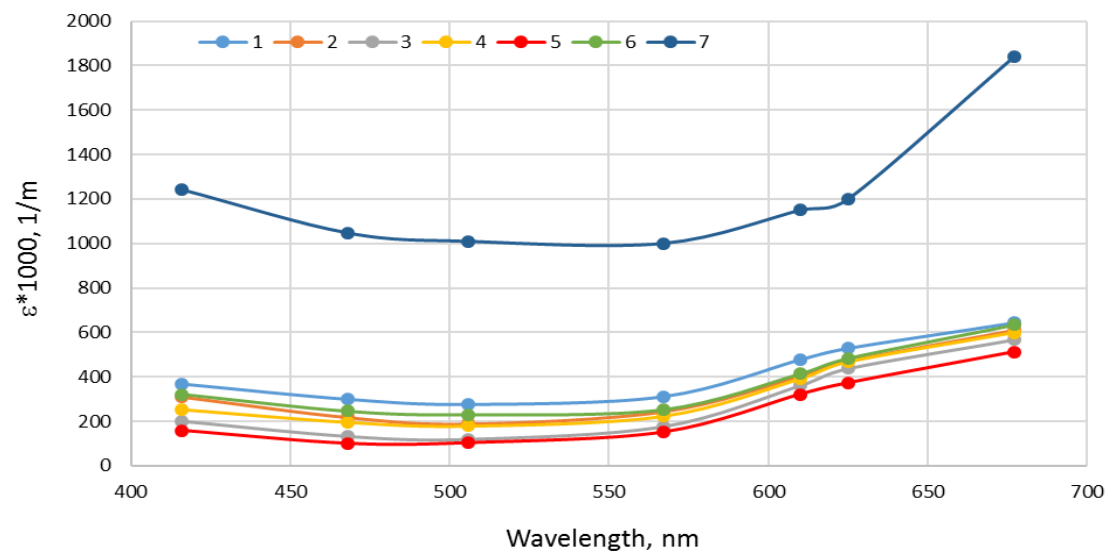

F i g. 4. Spectral characteristics of the beam attenuation coefficient in the Mediterranean Sea different regions (numbers 1-7 correspond to the region numbers) 
According to [18], the amount of yellow matter in the Mediterranean Sea is twice its content in the nearest Atlantic sector. In addition, the values of absorption coefficient $\kappa(442)_{\mathrm{ym}}$ by dissolved organic matter is almost $50 \%$ higher in the western part of the sea than in the eastern part. Spectra 1-5 (Fig. 4) reflect the indicated trend: due to an increase in the absorption coefficient of yellow matter in the direction from east to west of the Mediterranean Sea, the beam attenuation coefficient at $416 \mathrm{~nm}$ wavelength increases accordingly.

Light scattering phase functions. Fig. 5 shows the beam scattering coefficients, asymmetry coefficients, and average cosines of scattering in different regions. The spatial variability of the scattering coefficients is similar to the attenuation coefficient variability (Fig. 2). The reasons for this variability are discussed above.

T a b l e 5

Parameters of the light scattering phase functions

\begin{tabular}{c|c|c|c}
\hline $\begin{array}{c}\text { Region } \\
\text { number }\end{array}$ & Scattering coefficient $\sigma, 1 / \mathrm{m}$ & $\begin{array}{c}\text { Asymmetry } \\
\text { coefficient } K\end{array}$ & $\begin{array}{c}\text { Average cosine of } \\
\text { scattering, cos } \theta\end{array}$ \\
\hline 1 & 0.19 & 58.7 & 0.946 \\
2 & 0.21 & 77.8 & 0.960 \\
3 & 0.09 & 33.9 & 0.919 \\
4 & 0.15 & 56.0 & 0.944 \\
5 & 0.11 & 33.9 & 0.916 \\
6 & 0.17 & 54.6 & 0.944 \\
7 & 0.27 & 38.5 & 0.906 \\
\hline
\end{tabular}

Tab. 6 shows the minimum and maximum values of the phase function parameters observed in the Mediterranean Sea, and for comparison, similar phase function parameters in the Tropical Atlantic waters [19]. The comparison shows the proximity of the values of all parameters.

Ta b l e 6

\section{Range of the values of the phase function parameters observed in the Mediterranean Sea and the Tropical Atlantic [15]}

\begin{tabular}{c|c|c|c}
\hline Region & $\begin{array}{c}\text { Scattering } \\
\text { coefficient } \sigma, 1 / \mathrm{m}\end{array}$ & $\begin{array}{c}\text { Asymmetry } \\
\text { coefficient } K\end{array}$ & $\begin{array}{c}\text { Average cosine of } \\
\text { scattering, cos } \theta\end{array}$ \\
\hline $\begin{array}{c}\text { the } \\
\begin{array}{c}\text { Sea } \\
\text { Serranean }\end{array}\end{array}$ & $0.09-0.21$ & $34-78$ & $0.916-0.960$ \\
$\begin{array}{c}\text { the Tropical } \\
\text { Atlantic }\end{array}$ & $0.09-0.25$ & $34-77$ & $0.927-0.962$ \\
\hline
\end{tabular}


In the Mediterranean waters, a close relationship was observed between the asymmetry coefficient of the phase function and the scattering coefficient $K=f(\sigma)$ (Fig. 5). Such relations in water basins are regional and depend on the composition of the suspended matters in water [20]. In Fig. 5 shows the point for the Aegean waters near the Dardanelles, falling out of the $K=f(\sigma)$ relationship for the Mediterranean Sea. These parameter values refer to the waters of the Marmara Sea entering the Aegean Sea through the strait. The position of this point on the graph (Fig. 5) according to the model developed in [20] indicates a high concentration of fine suspended matter in the waters of the Marmara Sea.

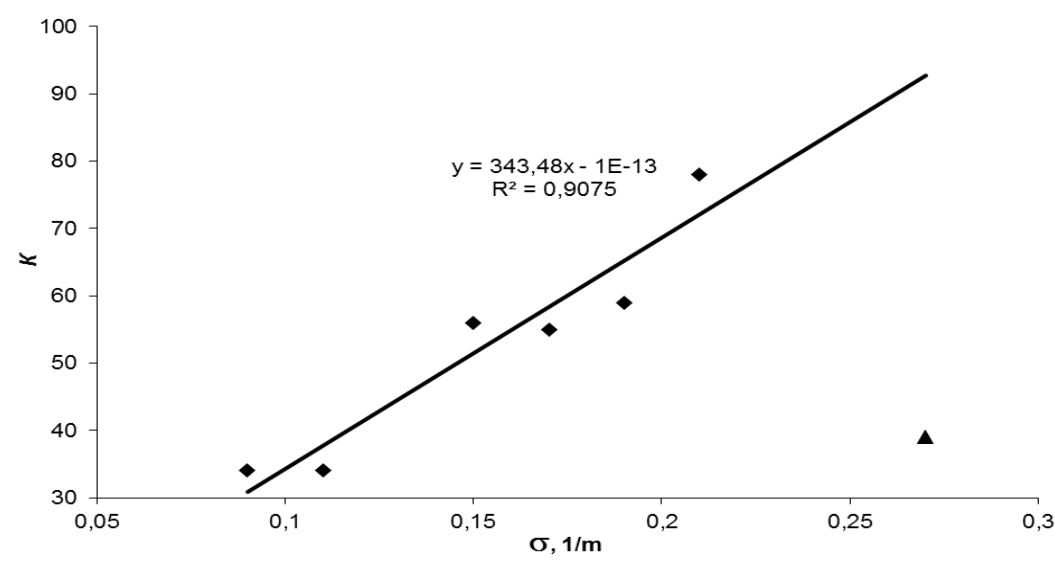

F i g. 5. Relationship between the asymmetry coefficient of scatterring phase function $K$ and the scattering coefficient $\sigma:-$ the Mediterranean Sea, $\boldsymbol{\Delta}$ - the Marmara Sea

Fig. 6 and Tab. 7 show examples of phase functions in the Mediterranean Sea and in the waters of the Marmara Sea.

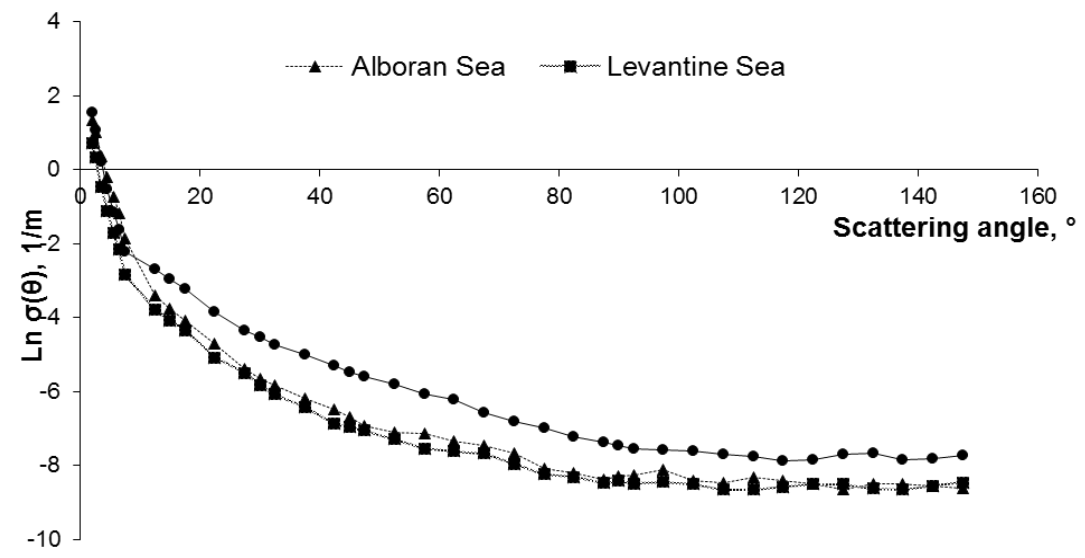

F i g. 6. Light scattering phase functions in the Mediterranean Sea: $\boldsymbol{\Delta}$ - the Alboran Sea (region 1); - - the Levantean Sea (region 5), - the Marmara Sea (region 7)

PHYSICAL OCEANOGRAPHY VOL. 27 ISS. 1 (2020) 
Table 7

The light scattering phase functions in the Mediterranean Sea waters

\begin{tabular}{|c|c|c|c|}
\hline \multirow{2}{*}{ Scattering angle $\theta,^{\circ}$} & \multicolumn{3}{|c|}{$\operatorname{Ln} \sigma(\theta), \mathrm{m}^{-1}$} \\
\hline & in region 1 & in region 5 & in region 7 \\
\hline 2.0 & 1.334 & 0.713 & 1.54 \\
\hline 7.5 & -1.863 & -2.852 & -2.23 \\
\hline 12.5 & -3.404 & -3.795 & -2.69 \\
\hline 17.5 & -4.094 & -4.347 & -3.22 \\
\hline 22.5 & -4.692 & -5.083 & -3.86 \\
\hline 27.5 & -5.397 & -5.505 & -4.35 \\
\hline 32.5 & -5.819 & -6.072 & -4.74 \\
\hline 37.5 & -6.187 & -6.417 & -4.99 \\
\hline 42.5 & -6.486 & -6.877 & -5.31 \\
\hline 47.5 & -6.923 & -7.061 & -5.61 \\
\hline 52.5 & -7.099 & -7.291 & 5.80 \\
\hline 57.5 & -7.130 & -7.544 & -6.07 \\
\hline 62.5 & -7.337 & -7.613 & -6.21 \\
\hline 67.5 & -7.452 & -7.682 & -6.56 \\
\hline 72.5 & -7.659 & -7.958 & -6.81 \\
\hline 77.5 & -8.073 & -8.234 & -6.99 \\
\hline 82.5 & -8.211 & -8.311 & -7.22 \\
\hline 87.5 & -8.372 & -8.472 & -7.38 \\
\hline 92.5 & -8.257 & -8.487 & -7.54 \\
\hline 97.5 & -8.119 & -8.441 & -7.57 \\
\hline 102.5 & -8.410 & -8.510 & -7.61 \\
\hline 107.5 & -8.479 & -8.648 & -7.71 \\
\hline 112.5 & -8.326 & -8.648 & -7.77 \\
\hline 117.5 & -8.418 & -8.579 & -7.87 \\
\hline 122.5 & -8.510 & -8.510 & -7.84 \\
\hline 127.5 & -8.648 & -8.510 & -7.70 \\
\hline 132.5 & -8.487 & -8.625 & -7.68 \\
\hline 137.5 & -8.487 & -8.648 & -7.84 \\
\hline 142.5 & -8.556 & -8.556 & -7.82 \\
\hline 147.5 & -8.625 & -8.464 & -7.73 \\
\hline
\end{tabular}




\section{Conclusion}

In May 1998, data characterizing spatial variability of the optical properties of the waters of the southern Mediterranean Sea in spring season were obtained from the measurements taken on R/V Gorizont.

The coefficients of beam attenuation and scattering in surface waters are gradually decreasing in the direction from the western Mediterranean Sea to the eastern one. The same spatial variability of the attenuation coefficient in the Mediterranean Sea in the spring (March - April 2018) is observed according to field data in [3].

In the Aegean Sea near the Dardanelles, the Marmara Sea waters are observed, characterized by high coefficients of the beam attenuation and scattering.

The parameters of light scattering phase functions in the Mediterranean Sea waters are similar to those in the Atlantic tropical waters.

In the Mediterranean Sea waters, as in other water basins, there is a relationship between the asymmetry coefficient of the light scattering phase function and scattering coefficient, which is manifested in increase of the phase function asymmetry coefficient with the scattering coefficient.

Presented data on the optical characteristics of the surface Mediterranean Sea waters can later be used for a comparative analysis of empirical data on the optics of Mediterranean waters obtained in the framework of field research and remote sensing of the Mediterranean Sea.

\section{REFERENCES}

1. Burenkov, V.I., Kopelevich, O.V., Sheberstov, S.V., Ershova, S.V. and Evdoshenko, M.A., 1999. Bio-Optical Characteristics of the Aegean Sea Retrieved from Satellite Ocean Color Data. In: P. Malanotte-Rizzoli and V. Eremeev, eds., 1999. The Eastern Mediterranean as a Laboratory Basin for the Assessment of Contrasting Ecosystems. Dordrecht: Springer, pp. 313-326.

2. Karageorgis, A.P., Georgopoulos, D., Kanellopoulos, T.D., Mikkelsen, O.A., Pagou, K., Kontoyiannis, H., Pavlidou, A. and Anagnostou, Ch., 2012. Spatial and Seasonal Variability of Particulate Matter Optical and Size Properties in the Eastern Mediterranean Sea. Journal of Marine Systems, 105-108, pp. 123-134. https://doi.org/10.1016/j.jmarsys.2012.07.003

3. Chaikalis, S., Velaoras, D., Karageorgis, A.P., Sofianos, S., Gogou, A., Cardin, V. and Hainbucher, D., 2018. LISST Measurements in the Mediterranean Sea: Relationships between Particle Optical Characteristics and Hydrology. In: Y.C. Agraval, A. Santos and O. Mikkelsen, 2018. $6^{\text {th }}$ Biennial Conference Particles in Europe, PiE-2018 (Lisbon, Portugal; 14-17 October 2018): Collection of Papers. Lisbon, Portugal, pp. 20-31. Available at: https://www.researchgate.net/publication/329365915_LISST_measurements_in_the _Mediterranean_Sea_Relationships_between_particle_optical_characteristics_and_h ydrology [Accessed: 10 January 2020].

4. Malanotte-Rizzoli, P., Artale, V., Borzelli-Eusebi, G.L., Brenner, S., Crise, A., Gacic, M., Kress, N., Marullo, S., Ribera d'Alcalà, M. [et al.], 2014. Physical Forcing and Physical/Biochemical Variability of the Mediterranean Sea: A Review of Unresolved Issues and Directions for Future Research. Ocean Science, 10(3), pp. 281-322. https://doi.org/10.5194/os-10-281-2014 
5. Mankovsky, V.I., Mishonov, A.V., Vladimirov, V.L. and Solov'ev, M.V., 1999. Optical Studies by the MHI of the Eastern Mediterranean: Available Data and Some Results. In: P. Malanotte-Rizzoli, V.N. Eremeev, eds., 1999. The Eastern Mediterranean as a Laboratory Basin for the Assessment of Contrasting Ecosystems. Dordrecht: Springer, pp. 127-139.

6. Afonin, E.I., Kaigorodov, M.N., Shemshura, V.E. and Shubina, A.A., 1973. Seasonal Variations of the Optical Structure of Water of the Strait of Gibraltar. In: MHI, 1973. Marine Hydrophysical Research. Sevastopol: MHI. No. 2, pp. 188-194.

7. Man'kovsky, V.I., Li, M.E. and Solov'ev, M.V., 1978. On Optical Structure of Waters in the Gulf of Lions and Its Chance after the Action of Mistral. In: MHI, 1978. Soviet-French Studies. Ocean-Atmosphere Interaction. Sevastopol: MHI, pp. 84-91.

8. Martynov, O.V., Vladimirov, V.L., Fedirko, V.I. and Kravtsov, G.L., 1984. HydroOptical Characteristics of the Levantine Sea Waters. In: K.S. Shifrin and B.I. Utenkov, eds., 1984. The Sea and the Atmosphere Optics: Abstracts (October 1984, Batumi). Leningrad, pp. 69-70.

9. Vladimirov, V.L. and Urdenko, V.A., 1985. Possible test Water Area for Calibrating Optical Satellite Devices. Issledovanie Zemli iz Kosmosa, (2), pp. 85-89 (in Russian).

10. Man'kovsky, V.I. and Solov'ev, M.V., 2002. Optical Parameters of the Izmir Bay and Influence of Izmir Sewage on Its. In: MHI, 2002. Ecological Safety of Coastal and Shelf Zones and Comprehensive Use of Shelf Resources. Sevastopol: MHI NANU. Iss. 1(6), pp. 93-109 (in Russian).

11. Man'kovsky, V.I., 2012. Spectral Contributions of the Components of Seawater to the Beam Attenuation Coefficient in Surface Waters of the Mediterranean Sea. Physical Oceanography, 21(5), pp. 305-319. https://doi.org/10.1007/s11110-0129124-z

12. Mankovsky, V.I., 2012. Spectral Laboratory Transparencymeter with Variable Base. In: MHI, 2012. Monitoring Systems of Environment. Sevastopol: MHI. Iss. 17, pp. 56-60.

13. Stambler, N., 2012. Underwater Light Field of the Mediterranean Sea. In: N. Stambler, Ed., 2012. Life in the Mediterranean Sea: A Look at Habitat Changes. Hauppauge, USA: Nova Science Publishers, Inc. Chapter 7, pp. 175-198.

14. Siokou-Frangou, I., Christaki, U., Mazzocchi, M.G., Montresor, M., Ribera d'Alcalá, M., Vaqué, D. and Zingone, A., 2010. Plankton in the Open Mediterranean Sea: A Review. Biogeosciences, 7(5), pp. 1543-1586. https://doi.org/10.5194/bg-7-15432010

15. Ryan, W.B.F., Olausson, E. and Fairbridge, R.W., 1966. Mediterranian Sea. In: R.W. Fairbridge, ed., 1966. The Encyclopedia of Oceanography. New York: Reinhold Publishing Corporation, pp. 490-499.

16. Dubravin, V.F., 2013. Biogeographical Structure. In: V.F. Dubravin, 2013. Atlas of Thermohaline and Biological Structure of Waters of the Atlantic Ocean. Kaliningrad: Kapros. Chapter 5, pp. 216-276 (in Russian).

17. Kopelevich, O.V., 1983. Small Parametric Model of Optical Properties of Sea Water. In: A.S. Monin, ed., 1983. Ocean Optics, Vol. 1: Physical Optics of Ocean. Moscow: Nauka, pp. 208-234 (in Russian). 
18. Morel, A. and Gentili, B., 2009. The Dissolved Yellow Substance and the Shades of Blue in the Mediterranean Sea. Biogeosciences, 6(11), pp. 2625-2636. https://doi.org/10.5194/bg-6-2625-2009

19. Mankovsky, V.I., 2018. Parameters of Scattering Phase Functions in Tropical Atlantic Waters. Atmospheric and Oceanic Optics, 31(6), pp. 604-610. https://doi.org/10.1134/S1024856018060106

20. Mankovskii, V.I., 2016. A Change in the Asymmetry Coefficient of LightScattering Phase Function in Natural Waters that Contain Organic Particles. Izvestiya, Atmospheric and Oceanic Physics, 52(3), pp. 328-333. https://doi.org/10.1134/S0001433816030087

About the authors:

Viktor I. Mankovsky, Senior Research Associate, Marine Hydrophysical Institute of RAS (2 Kapitanskaya St., Sevastopol, Russian Federation, 299011), Ph. D., ORCID ID: 0000-00024272-2218, ResearcherID: I-5460-2015, mankovskiy@mhi-ras.ru

Ekaterina V. Mankovskaya, Research Associate, Marine Hydrophysical Institute of RAS (2 Kapitanskaya St., Sevastopol, Russian Federation, 299011), Ph. D., ORCID ID: 0000-00024086-1687, ResearcherID: AAB-5303-2019, emankovskaya@mhi-ras.ru

Contribution of the co-authors:

Viktor I. Mankovsky - the problem statement, preparation of the article text, processing, interpretation and description of the study results, formulation of conclusions

Ekaterina V. Mankovskaya - selection and analysis of literature, presentation of data in the text and their analysis, preparation of graphic and text materials, article correction

All the authors have read and approved the final manuscript.

The authors declare that they have no conflict of interest. 